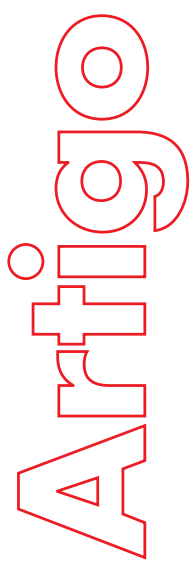

Revista

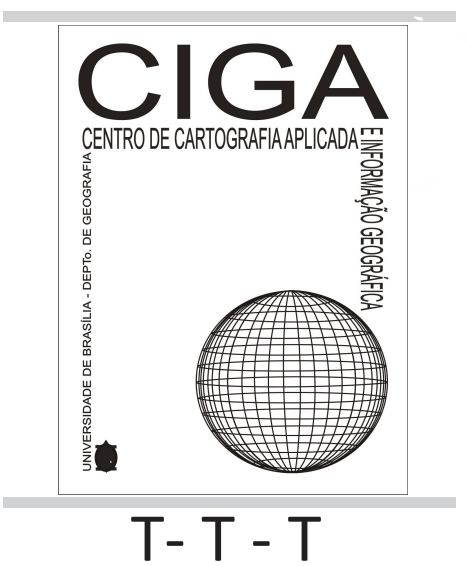

Revista Eletrônica: Tempo - Técnica - Território, V.11, N.2 (2020), 76:86 ISSN: 2177-4366

\section{GEOGRAFIA AFRICANA E AFROBRASILEIRA ANALISE DE LIVRO DIDATICO GEOGRAFIA GERAL E DO BRASIL: VOLUME ÚNICO}

\section{Agnes Cardoso Magalhães}

p. $76-86$

Como citar este artigo:

Magalhães, A.C.

GEOGRAFIA AFRICANA E AFROBRASILEIRA ANÁLISE DE LIVRO DIDÁTICO GEOGRAFIA GERAL E DO BRASIL: VOLUME ÚNICO Revista Eletrônica: Tempo - Técnica - Território, v.11, n.2 (2020),p.76:86 ISSN: 2177-4366.

Disponível em: http://periodicos.unb.br/index.php/ciga/

Este obra está licenciado com uma Licença Creative Commons Atribuição - Não Comercial 4.0 Internacional. 


\title{
GEOGRAFIA AFRICANA E AFROBRASILEIRA \\ ANÁLISE DE LIVRO DIDÁTICO \\ GEOGRAFIA GERAL E DO BRASIL: VOLUME ÚNICO
}

\begin{abstract}
Agnes Cardoso Magalhães
Graduanda em Comunicação Social pela Universidade de Brasília , Disciplina GEOAFRO -

1ํㅗㄹ
\end{abstract}

RESUMO: Este trabalho tem como objetivo propor uma análise a materiais didáticos utilizados em escolas públicas e privadas, especificamente o livro “Geografia Geral e do Brasil: Volume Único”, de Eustáquio de Sene e João Carlos Moreira, e definir sua completude ou carência no que diz respeito à abordagem das matrizes afro-brasileiras, e, por consequência, os limites de sua adequação à Lei 10.639/2003, que torna obrigatório o ensino de cultura e história africana e afro-brasileira no currículo educacional brasileiro.

Palavras-chave: Geografia; Continente africano; Afro-brasileiros; Sistema escravista; Material didático.

\begin{abstract}
This work aims to propose an analysis of didactic materials used in public and private schools, specifically the book “General and Brazilian Geography: Single Volume”, by Eustáquio de Sene and João Carlos Moreira, and to define its completeness or lack in what it says respect to the approach of Afro-Brazilian matrices, and, consequently, the limits of their adaptation to Law 10.639 / 2003, which makes the teaching of African and Afro-Brazilian culture and history mandatory in the Brazilian educational curriculum.
\end{abstract}

Keywords: Geography; African continent; Afro-Brazilians; Slavery system; Courseware.

\section{Introdução}

Diferentes momentos podem produzir diferentes reações ao mesmo estímulo. Quando um indivíduo se depara com um material didático na fase escolar da vida, quando é públicoalvo de tal publicação, não realiza análises críticas sobre o conteúdo ali apresentado, justamente por estar focado em absorver o que lhe é proposto. 
Configura-se, então, uma experiência totalmente nova a oportunidade de entrar em contato com uma obra como “Geografia Geral e do Brasil: Volume Único” na posição de estudante universitária e, assim, poder elaborar reflexões mais concretas sobre o que é lido.

O material a ser analisado neste artigo tem editoração da Scipione, São Paulo e, atualmente, se encontra em sua $6^{a}$ edição e foi escrito por Eustáquio de Sene e João Carlos Moreira.

É interessante observar a data de publicação e as relações que se estabelecem entre a época e a substância dos textos que se desenvolvem nela. Publicado em 2005, apenas dois anos depois da promulgação da Lei 10.639/2003, a obra reflete o esforço involuntário de incluir informações que tratem das relações étnico-raciais no Brasil, mas apenas no limite da inserção, apresentando, em diversas ocasiões, informações sem profundidade.

\section{Ficha Técnica}

Nome: Geografia Geral e do Brasil (Ensino Médio): Volume único

Autores: João Carlos Moreira e Eustáquio de Sene

Editora: Scipione, São Paulo

Ano: 2005, $1^{\text {a }}$ edição reformulada.

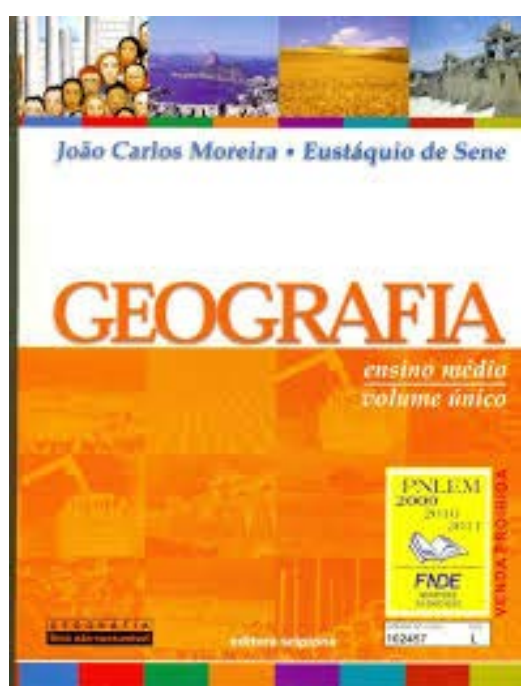

(Capa do livro)

Abordando a geografia geral e do Brasil, formulado voltando-se ao ensino médio, estruturalmente, o livro apresenta-se dividido em oito unidades, sendo estas subdivididas em 
capítulos que trazem sub temas pertinentes à unidade que compõem. Os conteúdos são divididos da seguinte forma:

1) Cartografia

- Capítulo 1: Localização e orientação

- Capítulo 2: Os mapas

- Capítulo 3: Representação gráfica

- Capítulo 4: Tecnologias modernas aplicadas à cartografia

2) Geografia física e meio ambiente

- Capítulo 1: Estrutura geológica

- Capítulo 2: As estruturas e as formas do relevo

- Capítulo 3: Clima

- Capítulo 4: Solo

- Capítulo 5: Hidrografia

- Capítulo 6: Biomas e formações vegetais: classificação e situação atual

3) Mundo contemporâneo: economia e geopolítica

- Capítulo 1: Processo de desenvolvimento do capitalismo

- Capítulo 2: O subdesenvolvimento

- Capítulo 3: Geopolítica e economia do período pós-Segunda Guerra

- Capítulo 4: O comércio internacional

4) Industrialização e geopolítica

- Capítulo 1: A geografia das indústrias

- Capítulo 2: A produção mundial de energia

- Capítulo 3: Reino Unido e França: os primeiros países a se industrializar

- Capítulo 4: Estados Unidos: o processo de industrialização da superpotência

- Capítulo 5: Alemanha: a emergência de uma potência

- Capítulo 6: Japão: do nascimento da potência à crise

- Capítulo 7: De União Soviética a Rússia: ascensão e queda de uma superpotência

- Capítulo 8: China: “a economia socialista de mercado”

- Capítulo 9: Os países emergentes

5) Brasil: industrialização e política econômica 
- Capítulo 1: Industrialização brasileira

- Capítulo 2: A economia brasileira contemporânea

- Capítulo 3: A produção de energia no Brasil

6) População

- Capítulo 1: Características e crescimento da população mundial

- Capítulo 2: Os fluxos migratórios e a estruturação da população

- Capítulo 3: A população brasileira

7) O espaço urbano e o processo de urbanização

- Capítulo 1: O espaço urbano do mundo contemporâneo

- Capítulo 2: As cidades e a urbanização brasileira

- Capítulo 3: Impactos ambientais urbanos

8) O espaço rural e a produção agrícola

- Capítulo 1: Atividades econômicas no espaço rural

- Capítulo 2: A agricultura brasileira

Ao final de cada unidade, o livro sugere fontes de pesquisa complementares, em formato de texto ou vídeo, e organiza uma série de exercícios extraídos de vestibulares e provas do ENEM, evidenciando partes de um caráter pragmático. A obra conta, por fim, com um glossário básico e bibliografia.

\section{Concepção de Geografia}

Tomando como base a escolha de assuntos a serem discutidos ao longo da publicação, mais do que possíveis opiniões e abordagens expressas implicitamente por trás dos fatos, é possível tomar um caminho em relação ao ponto de vista geográfico defendido pelos autores. À primeira vista, nos espaços reservados à apresentação e introdução contidas logo no início do livro, o que se expõe é uma preocupação com a preservação do passado, “[...] devendo ser considerado para a compreensão do presente e para o planejamento do futuro.”, segundo os autores.

Ainda nos escritos iniciais, na mesma página encontramos críticas à geografia puramente descritiva, alheia às relações entre natureza e sociedade, citações ao trabalho de Milton Santos, a colocação da expansão marítima europeia apenas como facilitadora de grandes 
avanços aos estudos geográficos, e pensadores da Grécia Antiga como os grandes analistas dos fenômenos naturais e estudiosos das paisagens naturais.

Esse conjunto que, inicialmente, levaria à conclusão de que o conteúdo do livro explicita uma concepção crítica dos fatos e do cenário geográfico mundial e brasileiro, como propõe, logo perde parte desse caráter quando analisada a profundidade alcançada em cada tópico, quase como se houvesse um limite imposto acerca do que é permitido esmiuçar e o que se deve deixar o mais intocado possível.

Assim sendo, por vezes o conteúdo se mostra apegado a dados estatísticos e a descrições que não se aprofundam intencionalmente, organizadas de forma a evitar a instigação crítica dos estudantes ou, pelo menos, não as incentivando. No fim, o que são oferecidas são citações a certos conteúdos - certamente para embasar declarações futuras sobre a presença destes na obra - e sugestões de pesquisas posteriores sobre certos temas, apenas. Essas são algumas incoerências presentes na publicação.

\section{Sistema Escravista}

Seria sutil a afirmação de que, em 560 páginas, o livro toca superficialmente no assunto do sistema escravista que fundamentou o Brasil e ainda determina a forma como o país se apresenta, nos dias de hoje. Longe de uma explicação digna sobre o assunto, as únicas referências ao passado colonial brasileiro se dão por meio de três abordagens: a) a da desapropriação das terras dos povos originários; b) das dificuldades encontradas por colonos para fomentar a industrialização do Brasil, após a abolição; c) da miscigenação que compôs o fenótipo da população brasileira, sendo mesmo a citação de termos como "escravidão” ou “negros” raras.

A única menção feita aos africanos que foram trazidos à América revela-se na página 447, em um box destinado à citação do livro “O povo brasileiro”, de Darcy Ribeiro. Nele, o autor explicita uma visão romantizada da mestiçagem brasileira, colocando-a como fator determinante na construção de uma nova estrutura societária, mas, outra vez, fazendo da dor de todo o período escravagista apenas uma alusão. Nas palavras de Ribeiro (1995), "Surgimos da confluência, do entrechoque e do caldeamento do invasor português com índios silvícolas e campineiros e com negros africanos, uns e outros aliciados como escravos.” 
Também a trajetória dos povos tradicionais da floresta aparece de forma breve, encaixando-se, por completo, em uma única página.

A pergunta, para a qual já se tem uma resposta, é por que um material didático utilizado em escolas públicas em turmas de ensino médio, cuja faixa etária já se encontra apta a discussões concretas sobre a Geografia e a História, se coloca em posição tão indiferente e ilusória acerca do nosso passado?

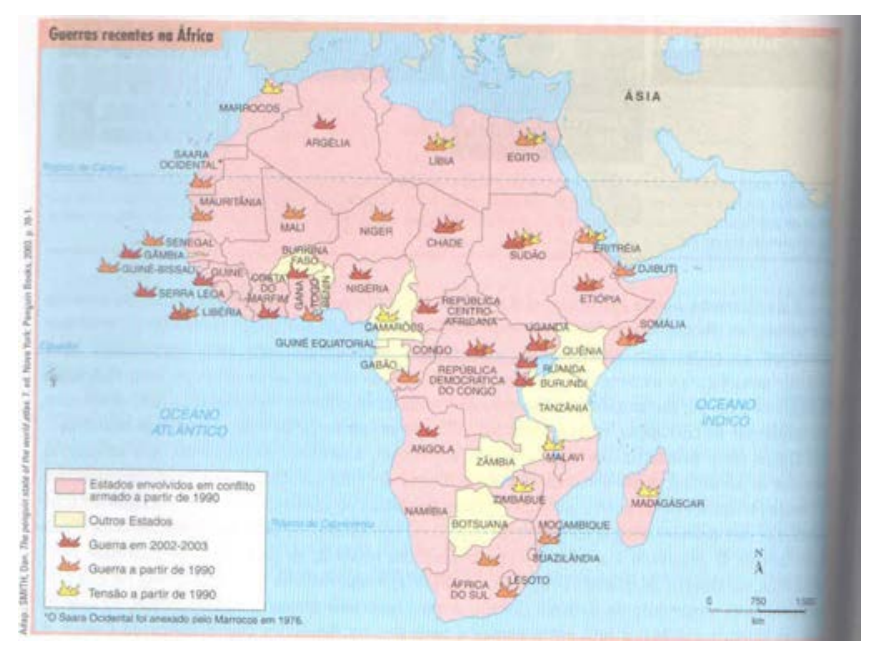

(Mapa representativo de conflitos recentes na África, um dos únicos destaques dados ao Continente em representação gráfica.)

\section{A Divisão Da Sociedade Brasileira Por Grupo Étnico E/Ou Cor}

Há, no capítulo 3 “A população brasileira” da sexta unidade do livro, a tabela a seguir, intitulada “Brasil: população residente classificada por cor ou raça - 2002”. 


\begin{tabular}{|c|c|c|c|}
\hline \multicolumn{4}{|c|}{ Brasil: populaçäo residente classificada por cor ou raça - 2002} \\
\hline Cor ou raça & $1950(\%)$ & $1980(\%)$ & $2002(\%)$ \\
\hline Branca & 61,7 & 54,7 & 53,3 \\
\hline Negra & 11,0 & 5,9 & 5,6 \\
\hline Parda & 26,5 & 38,5 & 40,5 \\
\hline Amarela & 0,6 & 0,6 & 0,4 \\
\hline Indigena* & - & - & 0,2 \\
\hline Sem declaração & 0,2 & 0,3 & - \\
\hline
\end{tabular}

(Tabela representativa da divisão por cor ou raça da população brasileira)

Acompanhando a tabela, os autores trazem uma breve explicação sobre o aumento da porcentagem de pessoas que se autodeclaram pardas durante as pesquisas do Censo Demográfico, entre os anos de 1950 e 2002. Segundo o livro,

Esses percentuais vêm diminuindo rapidamente, enquanto o número de pardos (40,5\%) vem aumentando. Esses índices demonstram que nesse período, assim como ao longo de toda a história do Brasil, houve uma intensa miscigenação, já que os grupos originais foram o indígena nativo, o negro africano e o branco europeu. (1995, p. 448)

Em consonância com o conteúdo do restante do material, Moreira e Sene optam por ocultar a realidade violenta que ocasionou, a princípio, a miscigenação entre os grupos citados, evidenciando a negação à discussão do racismo resultante dos séculos de escravidão, que também se evita abordar.

\section{Definição de Espaço Geográfico}

Segundo o conteúdo do livro, o espaço geográfico corresponde a toda área do planeta Terra. Habitando e compondo esse espaço estão os elementos e fenômenos passíveis de reprodução sobre esse espaço, que podem ser sociais ou naturais e convivem de forma sistêmica, ou seja, se inter-relacionam e influem uns aos outros. 
Algumas das categorias de fenômenos citadas pelos autores são as pontuais, as lineares e as zonais. Exemplos desses elementos e fenômenos são os recursos minerais naturais, as cidades, as redes de transporte (hidrovias, rodovias e ferrovias), as rotas aéreas, e os relevos.

Essa definição, entretanto, não se apresenta de forma estruturada e explícita em algum tópico temático, ou mesmo ao longo dos textos que compõem os capítulos, mas subentendida através de conceitos que pressupõem o conhecimento do que seria o espaço geográfico, em si, por quem lê. Mais do que como se conceitua, a obra dá grande importância às formas de representação do espaço e da paisagem, trazendo informações detalhadas sobre projeções cartográficas, os diferentes tipos de representação gráfica e o contexto histórico que consolidou a disposição do mundo como de praxe, hoje: com o norte em posição superior e a Europa como centro das relações do mundo, lógica antes inversa.

\section{Questões Étnico-Raciais no Brasil e Estereótipos}

Hoje, após cinco séculos vividos sob a lógica colonial no Brasil, é possível ter noção da contribuição africana e dos povos originários desta terra para a formação do país, e perceber que toda a sua estrutura ainda depende dessas comunidades. Ainda assim, direitos básicos como a demarcação territorial, o direito à prática religiosa e o conhecimento de sua história são negados de seu pleno exercício.

Esses estorvos manifestam-se, também, e principalmente, na configuração da educação brasileira e, consequentemente, no modo com que o período de formação escolar é vivenciado por crianças e jovens afro-brasileiros. Estar em idade tenra e ter passado a maior parte da vida — considerando a parcela desse grupo que dispõe desse privilégio - absorvendo versões da história, da geografia, da filosofia, entre outras disciplinas, que descartam a valorização da pessoa preta, enquanto enaltecem a cultura europeia e seus pensamentos, hábitos e feitos, é certamente um dos golpes mais violentos do racismo.

“Geografia - Volume único”, obra aqui analisada, não burla a usualidade desse fato. No capítulo 1 da Unidade 7, “O espaço urbano do mundo contemporâneo”, por exemplo, surge um dado interessante, que poderia ser motor de reflexões, mas que foi empregado de maneira indiferente. Ao alcançarem a discussão acerca das desigualdades e segregações espaciais, tema pertinente ao debate racial, os autores citam a problemática da violência urbana: 
“No Brasil, por exemplo, a violência atinge predominantemente jovens de 15 a 24 anos. Mas mesmo nessa faixa etária a violência é desigual: atinge mais os jovens do sexo masculino, sobretudo os negros. Enquanto a taxa geral de homicídios entre jovens é de 54,5/100.000, entre jovens brancos é de 39,3/100.000 e entre jovens negros é 68,4/100.000.” (p. 478)

Infelizmente, após o levantamento destes dados, nenhuma explicação ou análise sobre os motivos desse desequilíbrio é proposta, contentando-se os autores, mais uma vez, apenas com o descarte de fatos como se estes fossem uma realidade triste, porém sólida demais para que se tente entender ou modificar. Traça-se uma linha entre o profissional que, realmente, se preocupa em fazer críticas à relação sociedade-natureza-espaço para que se possa gerar cidadãos conscientes do mundo em que vivem, como é exposto como desejo na apresentação da obra, e aquele que procura desvencilhar-se de críticas à sua abordagem, de acordo com as temáticas que escolhe ou não abordar.

O exemplo utilizado sobre os dados de violência urbana podem ilustrar de forma verossímil a maneira como é tratada a população afro-brasileira, em matéria de relevância, ao longo desse conteúdo didático. Evitando o aprofundamento nas sequelas deixadas pela escravidão, não aborda-se as origens das desigualdades vivenciadas atualmente, gerando a sensação de que a História do Brasil só começa a partir do século XX. Curiosamente, todas as menções feitas aos descendentes da cultura africana no Brasil aparecem rápida ou negativamente, quando não os dois. Em outro momento, em referência a texto retirado do IBGE, que trata das estatísticas migratórias no Brasil, entre 1995 e 2000, encontramos outra amostra dessa dinâmica:

“A composição racial também é espelhada pela migração: 53,1\% dos emigrantes eram brancos, 40,1\% eram pardos, 5,1\% pretos, 0,7\% amarelos e $0,4 \%$ indígenas. O restante não se declarou dentro de nenhuma das categorias de cor ou raça.” (p. 450)

Salta à vista a percepção de que há, por trás do reconhecimento nas categorias de cor presentes no Censo, uma tentativa de invisibilização, já que mesmo em contextos protagonizados pela população negra — e não que reivindiquemos a posição de protagonismo nestes contextos especificamente negativos — há um mascaramento de personagens, sobretudo entre a divisão preto/pardo, porque ser visto de maneira estereotipada ou enviesada ainda é ser 
visto e, dentro dessas páginas, eu não me vejo. De maneira geral, o livro escolhe dar preferência às estatísticas de gênero, faixa etária e região.

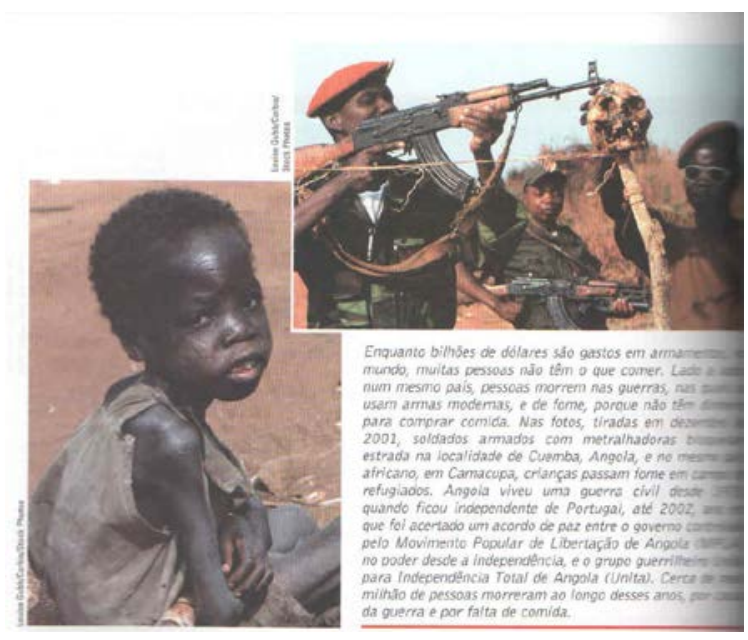

(Imagem utilizada pelo livro para ilustrar a situação do Continente Africano)

Ainda sobre representações estereotipadas, contudo, o continente Africano recebe destaque. Sempre que o assunto gira em torno de más condições de vida ou subdesenvolvimento, há um espaço reservado para o realce de África, inserido com a presença de frases como “sobretudo na África subsaariana”, escrita inúmeras vezes ao longo dos capítulos. Complementando a tentativa de degradação, em tom de julgamento, cita-se o cenário das guerras civis travadas pelos países africanos. No tópico em questão, aponta-se a pobreza como principal causa das guerras civis, mesmo reconhecendo a grande parcela de conflitos resultantes de uma divisão territorial imperialista que não respeitou as relações étnicas já presentes no continente. O que não se comenta, no entanto, é que ambos os motivos apontados como justificativa para essas guerras e os altos investimentos em militarização desses países, frente à demanda de estruturação social, foram provocados pela exploração europeia. 


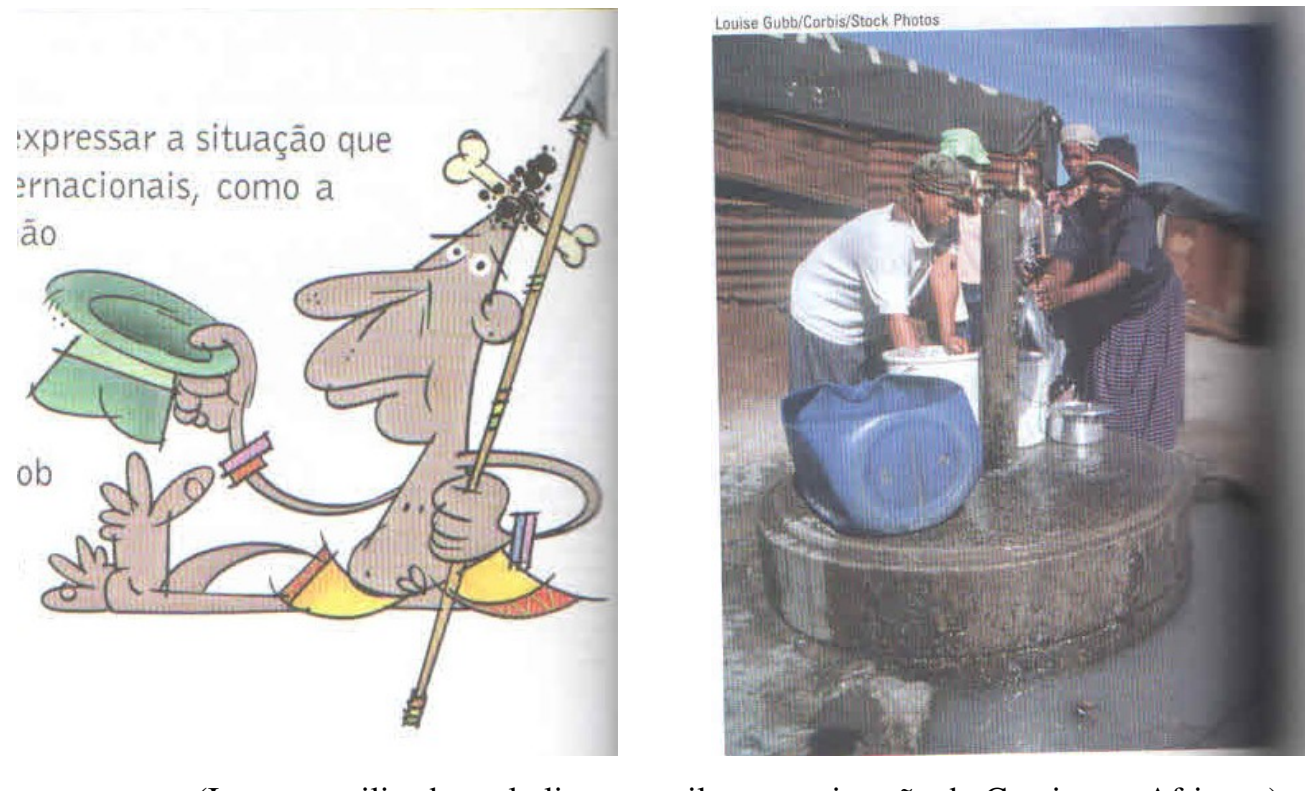

(Imagens utilizadas pelo livro para ilustrar a situação do Continente Africano)

As únicas imagens que representam pessoas pretas, tanto em ilustrações quanto fotografias, também reproduzem essa lógica de marginalização.

\section{Conclusões}

Escrever e publicar um material didático, certamente, não é tarefa das mais simples e, além de conhecimento, é preciso ter tato e segurança a respeito do conteúdo que se deseja desenvolver. Diante da análise deste material, percebemos que nem sempre as intenções e propostas previamente levantadas são, de fato, verídicas ou cumpridas da melhor forma.

O livro deixa transparecer o despreparo frente à discussão das relações étnico-raciais no Brasil e no mundo, e a desvalorização deste como fator determinante para a construção do que, hoje, é compreendido como a nação brasileira. Também, devido à época de publicação, e o fato de ter sido realizada a reformulação de uma edição recém publicada, sugere a adaptação às normas instituídas a partir da promulgação da Lei 10.639/2003, que tornou obrigatória a inserção do ensino de história e cultura africana e afro-brasileira nos currículos nacionais.

Como sugestão, seguindo a estrutura já proposta pelo livro, que recomenda pesquisas extracurriculares ao fim de cada capítulo e traz boxes com informações adicionais sobre assuntos enfáticos, geralmente de fontes externas, pode-se inserir conteúdos que supram, minimamente, a falta de debates que contemplem a história e cultura africana e afro-brasileira. A exemplo disso, o documentário “Atlântico Negro: Na Rota dos Orixás”, dirigido por Renato Barbieri, traça relações entre elementos da cultura brasileira e o tráfico transatlântico, podendo 
contribuir para o entendimento e valorização das raízes africanas no ambiente escolar. Aderindo, ainda, ao modelo que busca fontes especializadas, as reflexões construídas por Milton Santos no livro "Por uma Geografia nova: da crítica a uma geografia crítica”, citado na introdução da obra de Sene e Moreira, cairiam muito bem nas páginas centrais do material, não apenas em raras linhas.

\section{Referências}

ATLÂNTICO NEGRO: NA ROTA DOS ORIXÁS. Direção: Renato Barbieri. Produção de Videografia Criação e Produção. Brasil, 1998. Disponível em: $<$ https://www.youtube.com/watch?v=V1OqdhQItrI\&ab_channel=GAYAFilmes $>$. Acesso em 22 de março de 2021.

MOREIRA, João Carlos; DE SENE, J. E. Geografia Geral e do Brasil - Volume Único. $1^{\text {a }}$ Edição Reformulada. São Paulo: Editora Scipione, 2005.

RIBEIRO, Darcy. O povo brasileiro. A formação e o sentido do Brasil. São Paulo: Companhia das Letras, 1995. P 9-21.

SANTOS, Milton. Por uma Geografia Nova: da crítica a uma geografia crítica. São Paulo: Edusp, 2008. 